\title{
Lactation Ketoacidosis In A COVID- 19 Patient: A Case Report
}

\author{
Areej AlMweisheer and Aisha AlAtawi
}

\begin{abstract}
Lactation ketoacidosis is an uncommon cause of high anion gap metabolic acidosis affecting breastfeeding women due to increased metabolic demands, reduction in carbohydrate intake, and acute illness. Meanwhile, recent literature showed that COVID-19 might cause ketosis, ketoacidosis, and diabetic ketoacidosis. We report a case of a 22-year-old lady, four weeks postpartum, with a confirmed diagnosis of COVID-19. She presented with severe symptomatic ketoacidosis with a high anion gap, ketonuria and hypoglycemia that was due to lactation ketoacidosis. She was not tolerating orally for days because of abdominal pain, vomiting, and viral infection. After proper treatment in the ward for the presenting symptoms of lactation ketoacidosis and refeeding, she rapidly improved and discharged five days later. While ketoacidosis may be induced by starvation and/or lactation, it is our conclusion that the condition may be aggravated by COVID-19 infection. Emergency services should consider the risk of lactation ketoacidosis exacerbated by COVID19 in postpartum women.
\end{abstract}

Index Terms-COVID-19 ketoacidosis, anion gap metabolic acidosis, lactation ketoacidosis, ketosis, metabolic acidosis

\section{INTRODUCTION}

Metabolic acidosis is a potentially life-threatening medical problem characterized by low blood $\mathrm{pH}$ and a low serum bicarbonate concentration [1]. Metabolic acidosis may occur as a result of high anion gap metabolic acidosis (HAGMA) or loss of bicarbonate from the gastrointestinal tract or kidneys. HAGMA is commonly caused by diabetic ketoacidosis (DKA), lactic acidosis, renal insufficiency, and intoxications (e.g., methanol, ethanol, and salicylate) [2].

Lactation ketoacidosis and isolated starvation ketoacidosis are rare causes of HAGMA with only a few reported cases. Common underlying factors exacerbating HAGMA include intensive exercise, change in diet, skipping meals, or underlying illness. Meanwhile, a recent retrospective study had shown that COVID-19 might cause ketosis, ketoacidosis and diabetic ketoacidosis (DKA) [3]. The authors in that study hypothesized that COVID-19 might increase fat breakdown and thereby inducing ketosis and ketoacidosis.

Ketoacidosis in the lactating woman is rapidly reversible with appropriate treatment; hence, detailed medical history and clinical presentation assessment in addition to blood investigations are essential to identify the underlying cause of HAGMA and providing the appropriate treatment.

Until recently, no cases of either isolated starvation ketoacidosis nor lactation ketoacidosis were reported in association with COVID-19.

Areej AlMweisheer, Aisha AlAtawi are with Department of Emergency Medicine, King Fahad Medical City, Saudi Arabia, e-mail: areej.almweisheer@hotmail.com, e-mail: aalatawi@kfmc.med.sa

Areej AlMweisheer is the corresponding author.
Here, we report on a young, four months' postpartum lady with HAGMA despite no history of diabetes. She had been diagnosed with COVID-19 and showed gastrointestinal disturbances and abdominal pain.

\section{CASE PRESENTATION}

A 22-year-old lady, 4-month postpartum, presented to the emergency department (ED) with five days' history of nonspecific symptoms, including mild fever that is responding to antipyretics, nausea, vomiting, and abdominal pain. She had been diagnosed with COVID-19 five days before her presentation. Due to her worsened condition, she had been unable to tolerate any food intake in the preceding five days. She denied any change in bowel habits, jaundice, shortness of breath, chest pain, syncope, neurological manifestations, or skin changes. She did not have a history of diabetes, alcohol drink, or drug abuse.

On Arrival to ED, her vital signs revealed a blood pressure of $122 / 95 \mathrm{mmHg}$, a heart rate of 154 beats/min, a temperature of 37.8 degrees Celsius, and a respiratory rate of $22 \mathrm{breaths} / \mathrm{min}$, and point of care random blood sugar

$2.8 \mathrm{mmol} / \mathrm{L}$. The clinical examination revealed an anxiousill appearing woman and dry oral mucous membranes, with the rest of the physical examination being normal. Bedsides, abdominal ultrasound did not reveal any remarkable findings suggestive of abdominal pain.

Venous blood gas was taken, and revealed severe metabolic acidosis with PH: 7.06, partial pressure of carbon dioxide (PCO2): $18.2 \mathrm{kPa}$, bicarbonate (HCO3): $8.7 \mathrm{mmol} / \mathrm{L}$, lactate: $1.4 \mathrm{mmol} / 1$. A urine dipstick analysis revealed ketonuria $(+3)$. Moreover, her hemoglobin was $14.20 \mathrm{~g} / \mathrm{dl}$, leukocyte count $7.6710 \mathrm{e} 9 / 1$, serum creatinine $81 \mathrm{umol} / \mathrm{l}$, potassium $4.8 \mathrm{mmol} / \mathrm{l}$, chloride $111 \mathrm{mmol} / \mathrm{l}$, sodium $139 \mathrm{mmol} / \mathrm{l}$, and bicarbonate $<5.0 \mathrm{mmol} / \mathrm{l}$. She had high anion gap metabolic acidosis (HAGMA) with anion gap: $27.8 \mathrm{mmol} / \mathrm{l}$, enzymes revealed aspartate aminotransferase: 39 units/l, alanine aminotransferase: 62 units/l, and alkaline phosphatase 46 units/l. Additionally, her blood glucose level was $3.2 \mathrm{mmol} / \mathrm{L}$. On admission, chest X-ray did not show any signs of acute cardiopulmonary problems and a 12-lead electrocardiogram showed sinus tachycardia. Her serum albumin on admission was $52 \mathrm{~g} / \mathrm{L}$, and serum lactate was $0.80 \mathrm{mmol} / \mathrm{L}$. Besides, the blood alcohol level was negative. (references range for laboratory findings are included in table 1)

Based on the initial evaluation, she received in the ED 2 litres of normal saline, $50 \mathrm{ml}$ of $50 \%$ dextrose, $10 \mathrm{mg}$ of metoclopramide, and $1 \mathrm{gr}$ of paracetamol.

Differential diagnoses of HAGMA were taken into consideration including environmental causes, toxicology causes, 
TABLE I

LABORATORY VALUES UPON ADMISSION AND DURING ADMISSION COURSE

\begin{tabular}{|c|c|c|c|c|c|c|}
\hline Laboratory Value & Day 1 & Day 2 & Day 3 & Day 4 & Day 5 & Range \\
\hline $\mathrm{PH}$ & 7.06 & 7.37 & 7.46 & 7.46 & 7.47 & $7.35-7.45$ \\
\hline $\mathrm{pCO} 2(\mathrm{mmHg})$ & $<5.0$ & 22.6 & 21.8 & 24.5 & 20.5 & $41-51$ \\
\hline Serum Anion gap $(\mathrm{mmol} / \mathrm{L})$ & 27.8 & 11.2 & 14.0 & 12.6 & 16.4 & $8-12$ \\
\hline Serum lactate $(\mathrm{mmol} / \mathrm{L})$ & & 0.80 & 0.94 & & & $0.5-2.2$ \\
\hline Urine ketone $(\mathrm{mg} / \mathrm{dL})$ & positive & & & & & negative \\
\hline Serum osmolality $(\mathrm{mOsm} / \mathrm{kg})$ & & & & 281 & & \\
\hline Serum potassium $(\mathrm{mmol} / \mathrm{L})$ & 4.84 & 2.79 & 2.95 & 3.05 & 3.58 & $3.4-4.4$ \\
\hline Serum creatinine $(u m o l / L)$ & 81 & 36 & 44 & 46 & 43 & $49-90$ \\
\hline Glucose, plasma & 3.2 & 10.3 & & & & \\
\hline $\begin{array}{l}\text { Cortisol, serum }(\mathrm{nmol} / \mathrm{L}) \\
\text { Ethanol (Serum) }\end{array}$ & & & $\begin{array}{l}54(\mathrm{pm} \text { test }) \\
\text { negative }\end{array}$ & & & $\begin{array}{l}\text { am:101 - 536, } \\
\text { negative }\end{array}$ \\
\hline Lipase & 12 & & & & & \\
\hline
\end{tabular}

uremia, DKA, alcoholic ketosis, and lactic acidosis. However, given the patient's normal levels of lactic acid and cortisol, and toxicology result, these etiologies were ruled out. Furthermore, serum osmolality was normal. Our differential diagnosis was further narrowed due to the presence of elevated ketones. Given the patient's malnourished and postpartum state, the most likely cause of HAGMA was lactation ketoacidosis. She was admitted to our medical ward for further care.

Throughout the admission, she had multiple incidents of low random blood sugar and hypokalemia; however, work up for adrenal insufficiency was performed which came back negative. The patient was started on IV fluids of 5\% dextrose, sodium bicarbonate and electrolyte replacement. The patient was encouraged for gradual feeding from the second day of admission. Antibiotics, steroids, antiviral medication, and enoxaparin were started to manage the COVID-19 infection. After five days of admission, the patient had fully recovered and she was discharged in good health.

\section{DISCUSSION}

Ketoacidosis is a severe metabolic disorder characterized by the accumulation of ketone bodies and acidosis, is mostly seen in people with diabetes, and is rarely induced by other pathological conditions [4]. However, lactation ketoacidosis is a rare cause of HAGMA affecting breastfeeding mothers. Ketoacidosis has been reported to be induced by a low carbohydrate diet [5]. A negative energy balance due to any stressor exacerbates ketogenesis; thus, a stressor such as breastfeeding can produce lactation ketoacidosis [6].

In our case, a non-diabetic lactating woman presented with ketoacidosis. The patient had been diagnosed with COVID19 5-days before her presentation to the ED. Her nonspecific presenting symptoms were similar to those of lactation ketoacidosis, which could result from metabolic acidosis and hypoglycaemia. Due to her worsened condition, she had been unable to tolerate any food intake in the preceding five days. In light of a recent study which reported that COVID-19 might increase fat breakdown and induce ketosis which leads to ketoacidosis, it stands to reason that lactating women infected with COVID-19 should have a high carbohydrate diet to reduce the risk of ketoacidosis.

The mechanism of COVID-19-induced lactation ketoacidosis needs further research. However, a recent study showed that patients with COVID-19 commonly presented with reduced oral intake, and the suboptimal or poor feeding may result in high caloric deficits [7]. COVID-19 might further aggravate lactation ketoacidosis and can perhaps even be the trigger of this condition.

Our management approach in evaluating presenting symptoms and underlying factors, biomedical investigation, and treatment were consistent with the approach described in the systematic review of lactation ketoacidosis reported by Alawi et al., 2020. The main treatment of our case includes dextrose infusion and hydration, electrolytes replacement, a balanced diet, and treatment of the COVID-19.

\section{CONCLUSIONS}

This is a unique case of a postpartum lady with confirmed COVID-19 having lactation ketoacidosis. COVID-19 might be associated with lactation ketoacidosis and knowing this association would enhance considering this diagnosis in the appropriate population whenever having a COVID-19 suspected or confirmed case with ketosis and HAGMA.

\section{ACKNOWLEDGEMENTS}

The authors would like to express their very great appreciation to the patient for her contribution to this paper and would also like to show their appreciation for Mr Isamme AlFayyad - the clinical research specialist- for his valuable and constructive suggestions during the planning and development of this paper.

\section{REFERENCES}

[1] Kraut, J.A.; Madias, N.E. Metabolic acidosis: Pathophysiology, diagnosis and management. Nat. Rev. Nephrol. 2010, 6, 274-285.

[2] Lim, S. Metabolic acidosis. Acta Med. Indones. 2007, 39, 145-150.

[3] Li J, Wang X, Chen J, Zuo X, Zhang H, Deng A. COVID-19 infection may cause ketosis and ketoacidosis. Diabetes, Obesity and Metabolism. 2020 Apr 20.

[4] Larroumet A, Camoin M, Foussard N, Alexandre L, Mesli S, Redonnet I, Baillet-Blanco L, Rigalleau V, Mohammedi K. Euglycemic ketoacidosis induced by therapeutic fasting in a non-diabetic patient. Nutrition. 2020 Apr 1;72:110668. 
[5] Von Geijer L, Ekelund M. Ketoacidosis associated with low-carbohydrate diet in a non-diabetic lactating woman: a case report. Journal of medical case reports. 2015 Dec 1;9(1):224.

[6] Al Alawi AM, Al Flaiti A, Falhammar H. Lactation Ketoacidosis: A Systematic Review of Case Reports. Medicina. 2020 Jun;56(6):299.

[7] Aguila EJ, Cua IH, Fontanilla JA, Yabut VL, Causing MF. Gastrointestinal Manifestations of COVID-19: Impact on Nutrition Practices. Nutrition in Clinical Practice. 2020 Oct 1. 